\title{
Diagnostic and Prognostic Roles of Serum Osteopontin and Osteopontin Promoter Polymorphisms in Hepatitis B-related Hepatocellular Carcinoma
}

\author{
Nitinan Chimparlee ${ }^{1}$, Natthaya Chuaypen ${ }^{1}$, Apichaya Khlaiphuengsin ${ }^{1}$, Nutcha \\ Pinjaroen $^{2}$, Sunchai Payungporn${ }^{1}$, Yong Poovorawan ${ }^{3}$, Pisit Tangkijvanich ${ }^{1 *}$
}

\begin{abstract}
Background: The aims of this study were to evaluate the diagnostic and prognostic roles of serum osteopontin (OPN) and single nucleotide polymorphisms (SNPs) in the OPN promoter in patients with hepatitis B-related hepatocellular carcinoma (HCC). Materials and Methods: Four groups were studied, which included 157 patients with HCC, 73 with liver cirrhosis (LC) and 97 with chronic hepatitis $(\mathrm{CH})$, along with 80 healthy subjects. Serum OPN and alpha-fetoprotein (AFP) levels were measured. The SNPs -66 T/G, -156 G/ $\Delta$ G and -433 C/T within the OPN promoter were determined by direct sequencing. Results: Serum OPN levels were significantly higher in patients with HCC than in the other groups. Area under receiver operating characteristics curves in distinguishing HCC from chronic liver disease (CLD; CH and LC) were $0.782(95 \%$ CI; 0.729-0.834) for OPN and $0.888(95 \% \mathrm{CI}$; $0.850-0.927)$ for AFP. Using the optimal cut-off value $(70 \mathrm{ng} / \mathrm{mL})$, OPN had sensitivity and specificity of $72 \%$ and $71 \%$, respectively. Serum OPN was superior to AFP in detecting early-stage HCC (68\% vs. $46 \%$ ). A combination of both markers yielded an improved sensitivity for detecting early $\mathrm{HCC}$ to $82 \%$. A high OPN level was significantly correlated with advanced BCLC stage and was an independent prognostic factor for HCC. The SNPs -156 and $\mathbf{- 4 4 3}$ were associated with susceptibility to $\mathrm{HCC}$, but were not related to overall survival. Conclusions: Serum OPN is a useful diagnostic and prognostic marker for HCC. The combined use of serum OPN and AFP improved the diagnosis of early HCC. Genetic variation in the OPN promoter is associated with the risk, but not the prognosis of HCC.
\end{abstract}

Keywords: Osteopontin - alpha-fetoprotein - tumor marker - liver cancer - hepatitis B - polymorphisms

Asian Pac J Cancer Prev, 16 (16), 7211-7217

\section{Introduction}

Hepatocellular carcinoma (HCC) is one of the most common cancers worldwide, particularly in Southeast Asia, where hepatitis B virus (HBV) is highly prevalent (Forner et al., 2012). In Thailand, HCC represents one of the most common malignant tumors, with an incidence of 38.6 and 17.2 per 100,000 person-years in men and women, respectively.(El-Serag, 2012) Our previous data have shown that chronic HBV infection is the major cause of HCC in Thailand, accounting for at least $60 \%$ of cases (Tangkijvanich et al., 1999). Detection of HCC at an early stage is associated with a greater likelihood of curative treatment and improved survival of the patients (Bruix and Sherman, 2011). Currently, serum alpha-fetoprotein (AFP), a fetal-specific glycoprotein, has been the most widely used tumor marker for the detection and monitoring of HCC. However, serum AFP is not sensitive enough to identified early stage HCC and its level may be elevated in non-malignant chronic liver diseases (CLD), including chronic hepatitis $(\mathrm{CH})$ and liver cirrhosis (LC) (Sherman, 2011). Thus, the identification of alternative serum markers of HBV-related HCC is needed, particularly in low-resource regions with high incidence of HCC.

Osteopontin (OPN), an integrin-binding glycophosphoprotein, is expressed by several cell types and has been involved in both normal and pathological processes, such as cell adhesion, chemotaxis, matrix degradation, angiogenesis and apoptosis (Denhardt et al., 2001; Furger et al., 2001). It has been shown that OPN is over-expressed and associated with tumor invasion, progression and metastasis in various cancers, including HCC (Khodavirdi et al., 2006; Rohde et al., 2007; Korita et al., 2008; Sieghart et al., 2011). Given the detection in circulation, it appears that OPN can serve as a potential serum marker for early diagnosis and predicting the prognosis of HCC (Kim et al., 2006; Chen et al., 2010; Shang et al., 2012). Despite several studies reporting the 
use of serum OPN as a marker for $\mathrm{HCC}$, its diagnostic and prognostic value in comparison with AFP remains to be validated (Cheng et al., 2014). Moreover, a recent study demonstrated that single nucleotide polymorphisms (SNPs) at the promoter region of OPN, regulating its expression, might be a novel prognostic marker for HCC (Dong et al., 2013). However, data regarding the association of these SNPs with clinical correlations in patients with HCC are limited. To address these issues, we examined whether serum OPN represented a better diagnostic marker for $\mathrm{HBV}$-related $\mathrm{HCC}$ when compared to AFP. In addition, we examined the impact of serum OPN and its polymorphisms on clinical characteristics and outcome of these patients.

\section{Materials and Methods}

\section{Patients and samples}

Serum samples for the measurement of OPN levels were obtained from patients who were diagnosed with HBV-related HCC for the first time at King Chulalongkorn Memorial Hospital from January 2010 to December 2014. The diagnosis of HCC was based on typical imaging studies and/or histopathology according to American Association for the Study of Liver Diseases (AASLD) guideline.(Bruix and Sherman, 2011). Diagnostic criteria of HCC by imaging modalities were based on reports of focal lesions with hyperattenuation at the arterial phase, hypoattenuation at the portal phase in dynamic CT or MRI. In cases without typical imaging features liver biopsy/fine needle aspiration was performed to confirm the diagnosis of HCC.

The clinicopathological data of patients with $\mathrm{HCC}$ at initial diagnosis were collected, and HCC staging was classified into stages 0 and A to D based on Barcelona Clinic Liver Cancer staging system (BCLC) (Llovet et al., 2008). In this study, we classified tumors with BCLC stages 0 and A as early-stage HCC. The control groups comprised 3 groups included healthy volunteers with no apparent liver disease, patients with $\mathrm{CH}$ and patients with LC. The diagnosis of $\mathrm{CH}$ was based on persistence elevation of alanine transaminase (ALT) levels, while the diagnosis of LC was based on histopathology and/or clinical features such as the presence of ascites, or esophageal varices. All patients with HCC or CLD included in the current study were positive for serum hepatitis B surface antigen (HBsAg) for the previous 6 months. Patients with hepatitis $\mathrm{C}$ virus (HCV) and/or HIV co-infection were excluded. The study was approved by the Ethics Committee, Faculty of Medicine, Chulalongkorn University. Blood samples were obtained at initial presentation; sera were separated by centrifugation and stored at $-700 \mathrm{C}$ until tested.

\section{Measurement of serum OPN and AFP levels}

Serum OPN levels were measured by using an enzymelinked immunosorbent assay (ELISA) (R\&D Systems, Inc., Minneapolis, MN) according to the manufacturer's instructions. The OPN levels were calculated by a standard curve. Each serum sample was tested in duplicate and interpreted the result as $\mathrm{ng} / \mathrm{mL}$ (Kim et al., 2006). Serum AFP levels were determined using a commercially available ELISA kit according to the manufacturer's recommendations (Cobus'Core, Roche Diagnostics, Basel, Switzerland).

\section{DNA extraction and SNP genotyping}

The peripheral blood mononuclear cells (PBMCs) were isolated by Ficoll-Paque (Wisent Inc., St-Bruno, QC, Canada) and DNA were extracted by phenolchloroform-isoamyl alcohol extraction as described previously (Sopipong et al., 2013). The promoter of the OPN gene was amplified by forward primer: 5'-AGCTACTGCATACTCGAAATCAC-3' and reverse primer: 5' -CTGTACCTTGGTCGGCGTTT-3'. The thermal profiles started with initial denaturation $\left(95^{\circ} \mathrm{C}\right.$ for $3 \mathrm{~min}$ ), then followed by 40 cycles of amplification including denaturation $\left(95^{\circ} \mathrm{C}\right.$ for $\left.30 \mathrm{sec}\right)$, annealing $\left(57^{\circ} \mathrm{C}\right.$ for $30 \mathrm{sec})$ and extension $\left(72^{\circ} \mathrm{C}\right.$ for $\left.45 \mathrm{sec}\right)$. Finally, the process was completed with final extension step $\left(72^{\circ} \mathrm{C}\right.$ for $5 \mathrm{~min}$ ). The PCR product ( $598 \mathrm{bp}$ ) was analyzed by $2 \%$ agarose gel electropheresis and then purified by Hiyield Gel/PCR fragments extraction kit (RBC Bioscience, New Taipei City, Taiwan). The SNPs $-66 \mathrm{~T} / \mathrm{G},-156 \mathrm{G} / \Delta \mathrm{G}$ and $-433 \mathrm{C} / \mathrm{T}$ within OPN promoter were determined by direct sequencing (1st base, The Gemini, Singapore Science Park II, Singapore) followed by manufacturer's protocol and aligned with ClustalW Multiple alignment (BioEdit Sequence Alignment Editor, Version 7.0.4.1) program.

\section{Statistical analysis}

Data are expressed as percentage, mean and standard deviation. Comparisons between groups were analyzed by the $\chi^{2}$ or Fisher's exact test for categorical variables and by the Mann-Whitney test or Student's t test when appropriate for quantitative variables. Receiver-operating characteristics (ROC) curves were constructed to evaluate the diagnostic performance of the serum markers in discriminating $\mathrm{HCC}$ from $\mathrm{CH}$ and LC. Sensitivity, specificity, positive and negative predictive values and diagnostic accuracy were calculated in accordance with standard methods. Pearson correlation coefficient was used to evaluate the correlation between serum OPN and AFP levels. The analysis of overall survival of patients with HCC was calculated by the Kaplan-Meier method and the differences between groups were compared using the log-rank test. The Cox regression analysis was performed to identify factors influenced on overall survival. $\mathrm{P}$ values $<0.05$ were considered statistically significant. All statistical analyses were performed using the SPSS software for windows 21.0 (SPSS Inc., Chicago, IL).

\section{Results}

\section{Clinical characteristics}

Table 1 compares clinical characteristics of the subjects enrolled in this study. Patients with HCC and LC were significantly older than those with $\mathrm{CH}$ and healthy controls $(\mathrm{P}<0.001)$. However, there was no significantly difference in mean age between patients with HCC and LC. Patients with $\mathrm{CH}$ were significantly younger than healthy controls $(\mathrm{P}<0.001)$. In this study, there was no difference in sex distribution between groups $(\mathrm{P}=0.404)$. 
Serum OPN and AFP concentrations

Serum OPN levels in patients with $\mathrm{HCC}$ were significantly elevated compared with patients with $\mathrm{LC}, \mathrm{CH}$ and healthy controls $(\mathrm{P}<0.001)$. However, there was no significant difference in serum OPN levels among patients with LC, $\mathrm{CH}$ and healthy controls. (Table 1 and Figure 1A) Among patients with $\mathrm{HCC}$, there was no correlation between OPN and AFP values $(r=0.062 ; \mathrm{P}=0.442)$.

Serum AFP levels were also measured in the same serum samples. The level of serum AFP in patients with $\mathrm{HCC}$ was significantly higher than those of patients with LC, $\mathrm{CH}$ and healthy controls $(\mathrm{P}<0.001)$ (Figure 1B). Using the normal upper limit of AFP $(20 \mathrm{ng} / \mathrm{mL})$ as a cut-off point, AFP was elevated in $105(66.9 \%)$ patients with HCC.AFP values were within normal range in all healthy individuals, whereas values were elevated in $1(1.0 \%)$ of patients with $\mathrm{CH}$ and $4(5.5 \%)$ patients with LC. When using $200 \mathrm{ng} / \mathrm{mL}$ as a reference, AFP concentration was elevated in $80(51 \%)$ patients with $\mathrm{HCC}$ and $2(2.7 \%)$ of patients with LC. No patients with $\mathrm{CH}$ and healthy controls had serum AFP > $200 \mathrm{ng} / \mathrm{mL}$. (Table 1)

\section{Serum OPN and AFP as diagnostic markers}

The ROC curves for OPN and AFP were generated on the same graph to compare the diagnostic accuracies of the two markers. As shown in Figure 2A, the area under the curve (AUROC) of HCC and CLD (CH and LC) was 0.782
[95\% confidence interval (CI); 0.729-0.834, $\mathrm{P}<0.001$ ] for OPN and $0.888(95 \% \mathrm{CI}$; 0.850-0.927, $\mathrm{P}<0.001)$ for AFP. The combination of OPN and AFP only marginally increased AUROC for AFP alone $(0.905,95 \% \mathrm{CI}$; 0.8680.941, P<0.001). Similarly, the AUROC of HCC and LC was 0.769 (95\% CI; 0.709-0.829, $\mathrm{P}<0.001)$ for $\mathrm{OPN}$ and 0.883 (95\%CI; $0.840-0.926, \mathrm{P}<0.001)$ for AFP. The AUROC of combined OPN and AFP was 0.891 (95\%CI; 0.849-0.932, $\mathrm{P}<0.001$ ). (Figure $2 \mathrm{~B}$ )

Based on the ROC curve analysis, a cut-off point of serum OPN concentration considered as the highest accuracy for differentiating HCC from CLD or LC was comparable $(70 \mathrm{ng} / \mathrm{mL})$. At this concentration, the sensitivity, specificity and accuracy of the marker was approximately $72 \%, 64-71 \%$, and 69-71\%, respectively. When using the currently recommended clinical cutoff for AFP (20 ng/mL), the sensitivity, specificity and accuracy for the marker was approximately $67 \%, 94-97 \%$, and 76$83 \%$, respectively. The sensitivity, specificity, positive and negative predictive values, and accuracy of OPN, AFP and combined tests in differentiating HCC from the other groups are shown in Table 2.

Regarding HCC stage 0,7 of $9(77.8 \%)$ patients had elevated levels of serum OPN $\geq 70 \mathrm{ng} / \mathrm{mL}$, whereas 4 $(44.4 \%)$ patients had elevated serum AFP at cutoff value of $20 \mathrm{ng} / \mathrm{mL}$. When both serum OPN and AFP were determined in parallel, the sensitivity of the combined

Table 1. Clinical Characteristics and Serum Marker Levels of the Subjects

\begin{tabular}{lrrrrr}
\hline Group & No & $*$ Age $($ year $)$ & Sex $(\mathrm{M} / \mathrm{F})$ & \#OPN $(\mathrm{ng} / \mathrm{ml})$ & \#AFP $(\mathrm{ng} / \mathrm{ml})$ \\
Controls & 80 & $51.9 \pm 5.1$ & $68 / 12$ & $51.9(6.5-132.1)$ & $2.8(1.4-8.4)$ \\
CH & 97 & $45.8 \pm 8.8$ & $81 / 16$ & $51.5(3.7-218.8)$ & $2.8(0.9-361.1)$ \\
LC & 73 & $56.5 \pm 11.9$ & $56 / 17$ & $55.2(1.4-238.0)$ & $217.1(0.8-605000)$ \\
HCC & 157 & $57.3 \pm 9.7$ & $134 / 23$ & $133.2(1.0-3215.6)$ & \\
\hline
\end{tabular}

Controls=healthy volunteers; $\mathrm{CH}=$ chronic hepatitis; $\mathrm{LC}=$ liver cirrhosis; $\mathrm{HCC}=$ hepatocellular carcinoma $*$ Data express as mean $\pm \mathrm{SD}$; \#Data express as median (ranges)

A

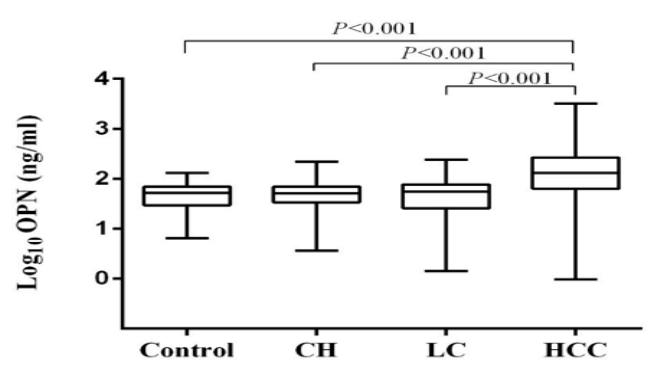

B

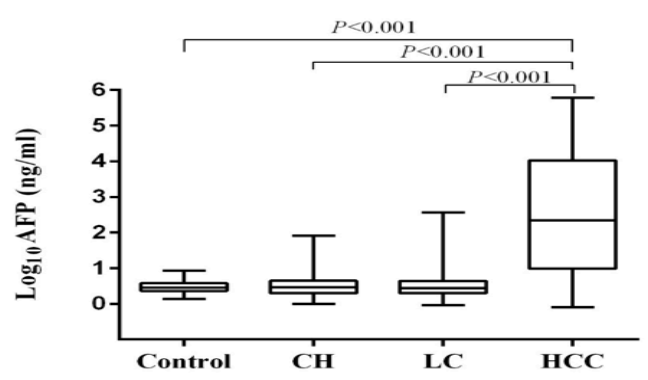

Figure 1. Serum OPN and AFP Levels in Each Group of Patients and Healthy Controls. (A) Log10 OPN (ng/ $\mathrm{ml})$. (B) $\log 10$ AFP (ng/ml)

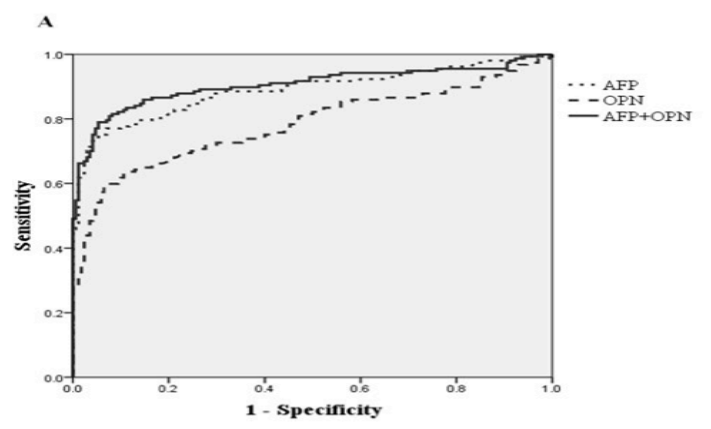

B

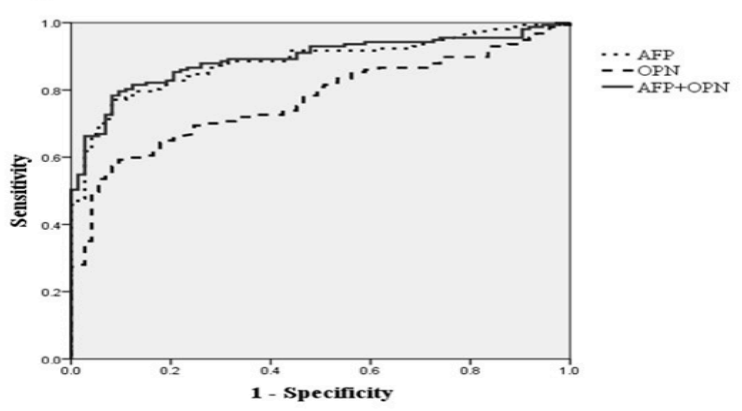

Figure 2. ROC Curves of Serum OPN and AFP in Differentiating HCC from Other Groups. (A) HCC and CLD. (B) HCC and LC 
test was $88.9 \%$. Regarding early-stage HCC (stages 0 and A), 19 of $28(67.9 \%)$ patients had elevated serum OPN, whereas $13(46.4 \%)$ patients had elevated serum AFP. When both serum markers were combined, the sensitivity was increased to $82.1 \%$. Among 52 patients with low AFP levels (AFP<20 ng/mL), $34(57.7 \%$ ) had increased serum OPN concentrations. The sensitivity of serum OPN, AFP and their combination in relation with BCLC staging is showed in Table 3.

\section{Polymorphisms in the promoter of $O P N$}

Prevalence of the SNPs in the promoter region of OPN gene in patients with $\mathrm{HCC}, \mathrm{CH}$ and $\mathrm{LC}$ is summarized in Table 4. There was no difference in the prevalence of SNP at locus -66. However, patients with $\mathrm{HCC}$ had a lower prevalence of SNP $-156 \Delta \mathrm{G} / \mathrm{G}$ and $-156 \Delta \mathrm{G} / \mathrm{G}$ plus $\mathrm{G} / \mathrm{G}$

Table 2. Serum OPN, AFP and Combination for Differentiation between HCC and Controls

\begin{tabular}{|c|c|c|c|c|c|}
\hline \multicolumn{2}{|c|}{$\begin{array}{c}\text { Sensitivity } \\
(\%)\end{array}$} & $\begin{array}{c}\text { Specificity } \\
(\%)\end{array}$ & $\begin{array}{l}\mathrm{PPV} \\
(\%)\end{array}$ & $\begin{array}{l}\text { NPV } \\
(\%)\end{array}$ & $\begin{array}{c}\text { Accuracy } \\
(\%)\end{array}$ \\
\hline \multicolumn{6}{|l|}{ HCC and CLD } \\
\hline OPN (70 ng/ml) & 72.0 & 70.6 & 69.3 & 73.2 & 71.3 \\
\hline AFP (20 ng/ml) & 66.9 & 97.1 & 95.5 & 76.0 & 82.6 \\
\hline OPN and AFP & 87.3 & 68.2 & 71.7 & 85.3 & 77.4 \\
\hline \multicolumn{6}{|l|}{$\mathrm{HCC}$ and $\mathrm{LC}$} \\
\hline OPN (70 ng/ml) & 72.0 & 64.4 & 81.3 & 51.6 & 69.6 \\
\hline $\operatorname{AFP}(20$ ng/ml) & 66.9 & 94.5 & 96.3 & 57.0 & 75.7 \\
\hline OPN and AFP & 87.3 & 60.3 & 82.5 & 68.8 & 78.7 \\
\hline \multicolumn{6}{|c|}{$\begin{array}{l}\mathrm{CH}=\text { chronic hepatitis; } \mathrm{LC}=\text { liver cirrhosis } \mathrm{HCC}=\text { hepatocellular } \\
\text { carcinoma; } \mathrm{PPV}=\text { positive predictive value; } \mathrm{NPV}=\text { negative predictive } \\
\text { value }\end{array}$} \\
\hline \multicolumn{6}{|c|}{$\begin{array}{l}\text { Table 3. The Sensitivity of Serum OPN, AFP and } \\
\text { Combination in Relation to HCC Staging }\end{array}$} \\
\hline BCLC Staging & $\begin{array}{r}\mathrm{OP} \\
(70 \mathrm{ng}\end{array}$ & $\begin{array}{l}\mathrm{N} \\
\mathrm{g} / \mathrm{ml})\end{array}$ & $\begin{array}{r}\mathrm{AF} \\
(20 \mathrm{ng}\end{array}$ & & $\begin{array}{c}\text { OPN and } \\
\text { AFP }\end{array}$ \\
\hline Stage $0(n=9)$ & $7(77$ & 7.8) & $4(44$ & & $8(88.9)$ \\
\hline Stage A $(n=19)$ & $12(6$ & 3.2) & $9(47$ & & $15(78.9)$ \\
\hline Stage $B(n=70)$ & $45(6$ & 4.3) & $45(64$ & & $59(84.3)$ \\
\hline Stage C,D $(n=59)$ & $49(8$ & $3.1)$ & $47(79$ & & $56(94.9)$ \\
\hline
\end{tabular}

compared with patients with CLD and LC. Patients carried $\Delta \mathrm{G} / \Delta \mathrm{G}$ genotype had similar mean OPN level compared to those with non- $\Delta \mathrm{G} / \Delta \mathrm{G}$ genotype $(\Delta \mathrm{G} / \mathrm{G}$ plus $\mathrm{G} / \mathrm{G})$ (365.1 \pm 652.6 vs $287.8 \pm 481.1 \mathrm{ng} / \mathrm{mL}, \mathrm{P}=0.416)$. Also, patients with HCC had a higher prevalence of SNP -443T/ $\mathrm{T}$ and $-443 \mathrm{~T} / \mathrm{T}$ plus $\mathrm{C} / \mathrm{T}$, when compared with patients with CLD and LC. Patients carried T/T or C/T genotypes tended to have higher mean OPN level compared to those with $\mathrm{C} / \mathrm{C}$ genotype, although the difference did not reach statistically significant (419.6 \pm 742.9 vs $256.4 \pm 384.9 \mathrm{ng} /$ $\mathrm{mL}, \mathrm{P}=0.110$ ).

Correlation of serum OPN and polymorphisms with disease characteristics and survival

To evaluate the association between serum OPN levels and clinical features, the patients with HCC were divided

Table 5. Relationship between Serum OPN Levels and Characteristics of Patients with HCC

\begin{tabular}{|c|c|c|c|}
\hline Variables & $\begin{array}{c}\text { Low OPN } \\
(<133 \mathrm{ng} / \mathrm{ml})\end{array}$ & $\begin{array}{l}\text { High OPN } \\
(\geq 133 \mathrm{ng} / \mathrm{ml})\end{array}$ & $P$ value \\
\hline \multicolumn{4}{|l|}{ Age (yrs) } \\
\hline$<60(\mathrm{n}=86)$ & 44 & 42 & \multirow[t]{2}{*}{0.683} \\
\hline$\geq 60(\mathrm{n}=71)$ & 34 & 37 & \\
\hline \multicolumn{4}{|l|}{ Gender } \\
\hline Male $(n=134)$ & 70 & 64 & \multirow[t]{2}{*}{0.122} \\
\hline Female $(n=23)$ & 8 & 15 & \\
\hline \multicolumn{4}{|l|}{ Child-Puge class } \\
\hline $\mathrm{A}(\mathrm{n}=121)$ & 71 & 50 & \multirow[t]{3}{*}{$<0.001^{*}$} \\
\hline$B(n=35)$ & 7 & 28 & \\
\hline$C(n=1)$ & 0 & 1 & \\
\hline \multicolumn{4}{|l|}{ BCLC tumor stage } \\
\hline $0(n=9)$ & 8 & 1 & \multirow[t]{4}{*}{$0.005^{*}$} \\
\hline$A(n=19)$ & 11 & 8 & \\
\hline$B(n=70)$ & 39 & 31 & \\
\hline$C(n=59)$ & 20 & 39 & \\
\hline \multicolumn{4}{|l|}{ SNP -156 (n=148) } \\
\hline $\mathrm{G} / \mathrm{G}+\mathrm{G} / \Delta \mathrm{G}(\mathrm{n}=76)$ & 34 & 42 & \multirow[t]{2}{*}{0.251} \\
\hline$\Delta G / \Delta G(n=72)$ & 39 & 33 & \\
\hline \multicolumn{4}{|l|}{ SNP -443 $(n=148)$} \\
\hline $\mathrm{C} / \mathrm{C}(\mathrm{n}=19)$ & 13 & 6 & \multirow[t]{2}{*}{0.075} \\
\hline $\mathrm{C} / \mathrm{T}+\mathrm{T} / \mathrm{T}(\mathrm{n}=129)$ & 60 & 69 & \\
\hline
\end{tabular}

Data expressed as n (\%)

Table 4. Prevalence of SNPs in the Promoter of OPN in Patients with HCC and Controls

\begin{tabular}{|c|c|c|c|c|c|c|c|c|}
\hline \multirow[t]{2}{*}{ SNPs } & \multirow{2}{*}{$\begin{array}{l}\mathrm{CH} \\
\mathrm{n}=82\end{array}$} & \multirow{2}{*}{$\begin{array}{l}\mathrm{LC} \\
\mathrm{n}=69\end{array}$} & \multirow{2}{*}{$\begin{array}{c}\text { CLD } \\
n=155\end{array}$} & \multirow{2}{*}{$\begin{array}{l}\text { HCC } \\
n=148\end{array}$} & \multicolumn{2}{|c|}{ HCC vs CLD } & \multicolumn{2}{|c|}{ HCC $v s$ LC } \\
\hline & & & & & OR $(95 \% \mathrm{CI})$ & $\mathrm{P}$ & OR $(95 \% \mathrm{CI})$ & $\mathrm{P}$ \\
\hline \multicolumn{9}{|l|}{ OPN (-66) } \\
\hline $\mathrm{T} / \mathrm{T}$ & $82(100 \%)$ & $69(100 \%)$ & $155(100 \%)$ & $131(88.5 \%)$ & - & - & - & - \\
\hline $\mathrm{T} / \mathrm{C}$ & & & & $7(4.7 \%)$ & & & & \\
\hline $\mathrm{C} / \mathrm{T}$ & & & & $10(6.8 \%)$ & & & & \\
\hline \multicolumn{9}{|l|}{ OPN (-156) } \\
\hline$(\Delta / \Delta)$ & $21(25.6 \%)$ & $23(33.3 \%)$ & $72(48.6 \%)$ & $44(29.1 \%)$ & 1.00 & & 1.00 & \\
\hline$(\Delta / \mathrm{G})$ & $44(53.7 \%)$ & $31(44.9 \%)$ & $31(20.9 \%)$ & $75(49.7 \%)$ & $0.25(0.14-0.44)$ & $<0.001^{*}$ & $0.32(0.16-0.63)$ & $0.001 *$ \\
\hline$(\mathrm{G} / \mathrm{G})$ & $17(20.7 \%)$ & $15(21.8 \%)$ & $45(30.5 \%)$ & $32(21.2 \%)$ & $0.86(0.48-1.55)$ & 0.614 & $0.96(0.45-2.03)$ & 0.911 \\
\hline$(\Delta / \mathrm{G})+(\mathrm{G} / \mathrm{G}$ & $61(74.4 \%)$ & $46(66.7 \%)$ & $76(51.4 \%)$ & $107(70.1 \%)$ & $0.43(0.27-0.70)$ & $0.001 *$ & $0.53(0.29-0.96)$ & $0.035^{*}$ \\
\hline \multicolumn{9}{|l|}{ OPN (-443) } \\
\hline $\mathrm{C} / \mathrm{C}$ & $13(15.9 \%)$ & $20(29.0 \%)$ & $19(12.8 \%)$ & $33(21.9 \%)$ & 1.00 & & 1.00 & \\
\hline $\mathrm{C} / \mathrm{T}$ & $33(40.2 \%)$ & $15(21.7 \%)$ & $45(30.4 \%)$ & $48(31.8 \%)$ & $1.63(0.81-3.26)$ & 0.170 & $3.16(1.34-7.45)$ & $0.009 *$ \\
\hline $\mathrm{T} / \mathrm{T}$ & $36(43.9 \%)$ & $34(49.3 \%)$ & $84(56.8 \%)$ & $70(46.3 \%)$ & $2.08(1.09-3.98)$ & $0.026^{*}$ & $2.60(1.24-5.47)$ & $0.012 *$ \\
\hline $\mathrm{C} / \mathrm{T}+\mathrm{T} / \mathrm{T}$ & $69(84.1 \%)$ & $49(71.0 \%)$ & $129(87.2 \%)$ & $118(78.1 \%)$ & $1.90(1.02-3.52)$ & $0.042 *$ & $2.77(1.36-5.63)$ & $0.005^{*}$ \\
\hline
\end{tabular}

$\mathrm{SNP}=$ Single nucleotide polymorphism; $\mathrm{CH}=$ chronic hepatitis; $\mathrm{LC}=$ liver cirrhosis; $\mathrm{HCC}=$ hepatocellular carcinoma; $\mathrm{OR}=\mathrm{Odd}$ ratio; $\mathrm{CI}=$ confidence intervals 


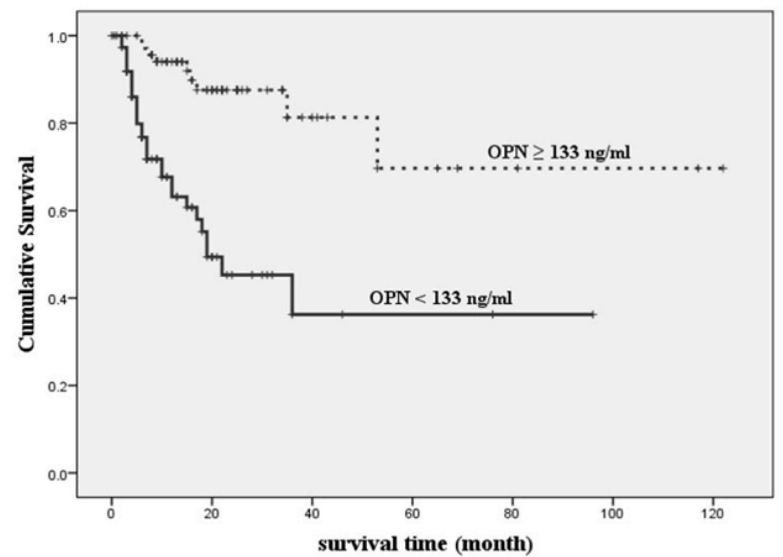

Figure 3. Overall Survival of Patients with HCC Regarding to Serum OPN Levels

into two groups based on the median value of the marker (133 ng/mL). Accordingly, there were 78 and 79 patients with low and high levels of serum OPN, respectively. The correlations between groups and various clinical parameters listed in Table 5 were analyzed. There was no significant correlation between serum OPN level and patient age, gender and the SNP at locus -156. However, high serum OPN levels were significantly found in patients with Child-Puge $\mathrm{B}$ and $\mathrm{C}(\mathrm{P}<0.001)$ and advanced BCLC stage $(\mathrm{P}=0.005)$. Patients carried non- $\mathrm{C} / \mathrm{C}(\mathrm{C} / \mathrm{T}$ plus $\mathrm{T} / \mathrm{T}$ genotypes) of the SNP -443 tended to have higher levels of OPN than those with $\mathrm{C} / \mathrm{C}$ genotype, though not significantly different $(\mathrm{P}=0.075)$.

The potential prognostic value of serum OPN was also analyzed. The overall survival of patients with low OPN levels $(<133 \mathrm{ng} / \mathrm{mL})$ was significantly better than that of patients whose serum levels were $\geq 133 \mathrm{ng} / \mathrm{mL}$ ( $\mathrm{P}<0.001$ by log rank test). (Figure 3) However, the overall survival of patients carried $\Delta \mathrm{G} / \Delta \mathrm{G}$ and non $-\Delta \mathrm{G} / \Delta \mathrm{G}$ genotype of the SNP -156 were not different $(\mathrm{P}=0.458$ by log rank test). The overall survival of patients carried $\mathrm{C} / \mathrm{C}$ and non- $\mathrm{C} / \mathrm{C}$ genotypes of the SNP -443 were also not significantly different $(\mathrm{P}=0.639$ by $\log$ rank test $)$.

Serum OPN level, the SNP - 156 and SNP -443 were entered into the multivariate analysis together with other variables that might influence prognosis. These factors included age, gender, serum AFP level, Child-Pugh score and BCLC stage. The multivariate analysis using the Cox proportional hazards model revealed that high serum OPN (risk ratio; 2.517, 95\%CI; 1.251-5.064, $\mathrm{P}=0.010$ ), high serum AFP (risk ratio; 2.455, 95\%CI; 1.144-5.268, $\mathrm{P}=0.021$ ), and advanced BCLC stage (risk ratio; 1.578 , 95\% CI; 1.001-2.486, $\mathrm{P}=0.049$ ) were independent prognostic factors of overall survival. However, the SNP -156 (risk ratio; 0.866, 95\%CI; 0.616-1.217, $\mathrm{P}=0.407$ ) and the SNP -443 (risk ratio; 1.142, 95\%CI; 0.704-1.854, $\mathrm{P}=0.591$ ) were not associated with overall survival of patients with HCC.

\section{Discussion}

Hepatocarcinogenesis is a multistage process with the majority of cases involving underlying $\mathrm{CH}$ and LC (Llovet et al., 2003). In Thailand, which is an endemic area of viral hepatitis, infection rates of HBV have exceeded $60 \%$ of patients with CLD, reflecting a potential risk for HCC development in the future (Tangkijvanich et al., 1999; Chittmittrapap et al., 2013). Currently, the measurement of AFP has been routinely used as a serum marker for detecting and monitoring HCC. AFP is a glycoprotein expressed abundantly in fetal liver, which can be reexpressed in adults by the tumor cells with respect to their differentiation (Taketa, 1990). Although AFP has a high sensitivity in detecting advanced stages of HCC, its sensitivity decreases significantly for the detection of small tumors (Debruyne and Delanghe, 2008). In addition, a significant increase in serum AFP level (20-200 ng/mL) could be found in a proportion of patients with $\mathrm{CH}$ and LC (Yuen and Lai, 2005; Spangenberg et al., 2006). As shown in this report, the overall sensitivity of AFP for differentiating HCC from CLD at a cut-off value of 20 $\mathrm{ng} / \mathrm{mL}$ was $67 \%$. However, the sensitivity of the test in differentiating early HCC from CLD declined to $46 \%$.

In this study, we found that serum OPN levels were significantly higher in patients with HCC than healthy controls and patients with CLD, suggesting that serum OPN may serve as a potential diagnostic marker for HCC. Using the best cut-off value, the sensitivity and specificity of the serum maker for discriminating HCC from CLD were $72 \%$ and $71 \%$, respectively. However, it should be mentioned that the sensitivity and specificity of serum OPN in this study were somewhat lower than previously reported in most studies. In a recent meta-analysis, for example, the pooled sensitivity and $95 \% \mathrm{CI}$ for OPN was $0.86(0.79-0.91)$, while the pooled specificity was 0.86 (0.69-0.94). The pooled data also demonstrated that the diagnostic accuracy of OPN was comparable to, if not better than, that of AFP in terms of the AUROC (0.92 vs 0.87)(Wan et al., 2014). In contrast, our data revealed a lower diagnostic accuracy of OPN in differentiating HCC from CLD when compared with AFP (the AUROC; 0.78 vs 0.89). Interestingly, some recent studies also reported that the AUROC for OPN was significantly lower that of AFP, suggesting a non-superior accuracy to AFP for the diagnosis of HCC (Lee et al., 2014; Simao et al., 2015). A possible explanation of this discrepancy among reports is unclear but might be related to the heterogeneity of population studied.

In agreement with previous reports, our data showed that the simultaneous measurement of OPN and AFP could significantly increase the sensitivity for detecting HCC (Wan et al., 2014). These results could be explained by the fact that there was no correlation between OPN and AFP values in the majority of cases of HCC. Another important issue to be mentioned is whether OPN would be a better marker for the detection of early HCC compared to AFP. Indeed, the diagnosis of HCC at an early stage is essential and has a high clinical relevance since it can be more effectively treated with curative therapies (Bruix and Sherman, 2011). Clinically, ultrasonography represents a method of choice for HCC surveillance. However, its use is limited for detecting small $\mathrm{HCC}$, with a sensitivity of approximately $60 \%$ and the determination of AFP provides no additional benefit to ultrasonography (Singal et al., 2009). Regarding serum OPN, a recent study 


\section{Nitinan Chimparlee et al}

demonstrated that its performance was higher than AFP in comparing cirrhosis and early HCC (Shang et al., 2012). Furthermore, in a prospective cohort including patients who eventually developed HCC, OPN levels were already increased several months before the diagnosis of the cancer (Shang et al., 2012). In this study, our data showed a higher proportion of early-stage HCC (stages 0 and A) had elevated OPN levels compared with AFP (68\% and $46 \%$, respectively), and the combination of these markers yielded an improved sensitivity for detecting early HCC to $82 \%$. Thus, it appears that measurement of serum OPN or combined with AFP may be more advantageous than AFP alone for the diagnosis of early HCC. Nonetheless, additional studies including a larger number of patients are required to confirm this observation.

OPN is a multifunctional protein that involves in several pathological conditions including cancer progression. Although the exact its biological functions on hepatocarcinogenesis are still not well understood, it has been reported in vitro and in vivo that OPN plays important roles in tumor aggressiveness and metastasis(Nagoshi, 2014). In this report, OPN levels significantly increased with progressive deterioration of underlying liver function in terms of Child-Pugh class and advancing BCLC tumor stages. Indeed, a positive correlation between serum OPN levels and HCC stage has been consistently shown in previous studies (Cheng et al., 2014). These data suggest that serum OPN might be useful in clinical setting to predict tumor progression and stage. A high-serum OPN level was also a significant prognostic factor in terms of overall survival, as demonstrated by multivariate analysis. These results were in agreement with previous reports suggesting that serum OPN levels are related to the prognosis of patients various malignant diseases, including gastric and breast cancers (Bramwell et al., 2006; Wu et al., 2007). Among patients with HCC, several studies have showed that OPN over-expression in liver tissue is linked to poor prognosis and may have predictive potential for tumor invasion and metastasis (Zhang et al., 2012). In a recent meta-analysis, current evidence indicates that serum OPN has significant predictive ability for estimating survival in HCC (Cheng et al., 2014). In patients after curative resection of HCC, postoperative monitoring serum OPN could serve as a surrogate marker for treatment response and tumor recurrence, including those with AFP-negative (Zhou et al., 2013). Collectively, it appears that serum OPN not only is useful for diagnosis of HCC, but also implies its prognostic role at initial presentation or after curative therapy of $\mathrm{HCC}$.

Polymorphisms in the OPN promoter may result in changes of transcriptional activity, and have been reported to be associated with the pathogenesis of liver diseases, including chronic HCV infection and HCC (Sakaki et al., 2010; Dong et al., 2013). A recent study demonstrated that patients carried T/T or T/C genotypes of the SNP $-433 \mathrm{had}$ a shorter overall survival compared with those with $\mathrm{C} / \mathrm{C}$ genotype. Moreover, T/T genotype could significantly increase transcriptional activity and expression level of OPN compared with the protective $\mathrm{C} / \mathrm{C}$ genotype. These findings indicated that the SNP could affect the prognosis of HCC by up-regulating the expression of OPN. In this study, our data provided evidence for the first time that the SNP -156 and SNP -443, but not SNP -66, were significantly associated with susceptibility to HCC. Specifically, patients carried $\Delta \mathrm{G} / \Delta \mathrm{G}$ genotype of the SNP -156 or T/T genotype of the SNP -443 had approximately 2-fold increased risk of HCC development. Despite their association with the development of $\mathrm{HCC}$, the correlation with serum OPN levels and the prognostic significance of these SNPs was not well documented in this report. Instead, serum OPN level was identified as an independent factor associated with the prognosis of HCC.

This study might have some limitations. First, the sample size of early stages of HCC was rather small. This limitation might reflect the fact that most Thai patients already have advanced tumor stages at initial presentation. Second, we included only patients with chronic HBV infection and other causes of CLD such as chronic HCV infection, alcoholic steatohepatitis (ASH) and non-alcoholic steatohepatitis (NASH) were excluded. Thus, these data could not response the question whether serum OPN has a similar performance in patients with HCV-, ASH- or NASH-related HCC. Finally, our study included only Thai patients, which might not be applicable to other ethnic populations.

In conclusion, our study showed that serum OPN levels were significantly elevated in patients with early and advanced HCC compared to patients with CLD and healthy controls. There was no correlation between serum OPN and AFP levels, suggestive of the complementary role of the two markers in the diagnosis of HCC. A high serum OPN level at initial presentation was an unfavorable prognostic marker for HCC. Host genetic variations in the promoter of OPN were associated with HCC risk, but were not related to the overall survival. Further large scale studies are required to confirm these observations and to validate the clinical significance of serum OPN and its polymorphisms in patients with $\mathrm{HCC}$.

\section{Acknowledgements}

This study was supported by the Rajadapiseksompoj research grant, Faculty of Medicine, Chulalongkorn University. The study was also supported by National Research University Project, Office of Higher Education Commission (WCU011-HR57) and the Ratchadaphiseksomphot Endowment Fund of Chulalongkorn University (CU-57-001-HR). We would like to thank all the staff of Research Unit of Hepatitis and Liver Cancer and Center of Excellence in Clinical Virology, Faculty of Medicine, Chulalongkorn University.

\section{References}

Bramwell VH, Doig GS, Tuck AB, et al (2006). Serial plasma osteopontin levels have prognostic value in metastatic breast cancer. Clin Cancer Res, 12, 3337-43.

Bruix J, Sherman M (2011). Management of hepatocellular carcinoma: an update. Hepatology, 53, 1020-2.

Chen RX, Xia YH, Cui JF, et al (2010). Osteopontin, a single marker for predicting the prognosis of patients with tumornode-metastasis stage I hepatocellular carcinoma after 
surgical resection. J Gastroenterol Hepatol, 25, 1435-42.

Cheng J, Wang W, Sun C, et al (2014). Meta-analysis of the prognostic and diagnostic significance of serum/ plasma osteopontin in hepatocellular carcinoma. J Clin Gastroenterol, 48, 806-14.

Chittmittrapap S, Chieochansin T, Chaiteerakij R, et al (2013). Prevalence of aflatoxin induced p53 mutation at codon 249 (R249s) in hepatocellular carcinoma patients with and without hepatitis B surface antigen (HBsAg). Asian Pac J Cancer Prev, 14, 7675-9.

Debruyne EN, Delanghe JR (2008). Diagnosing and monitoring hepatocellular carcinoma with alpha-fetoprotein: New aspects and applications. Clin Chim Acta, 395, 19-26.

Denhardt DT, Giachelli CM, Rittling SR (2001). Role of osteopontin in cellular signaling and toxicant injury. Annu Rev Pharmacol Toxicol, 41, 723-49.

Dong QZ, Zhang XF, Zhao Y, et al (2013). Osteopontin promoter polymorphisms at locus -443 significantly affect the metastasis and prognosis of human hepatocellular carcinoma. Hepatology, 57, 1024-34.

El-Serag HB (2012). Epidemiology of viral hepatitis and hepatocellular carcinoma. Gastroenterology, 142, 1264-73 .

Furger KA, Menon RK, Tuck AB, et al (2001). The functional and clinical roles of osteopontin in cancer and metastasis. Curr Mol Med, 1, 621-32.

Khodavirdi AC, Song Z, Yang S, et al (2006). Increased expression of osteopontin contributes to the progression of prostate cancer. Cancer Res, 66, 883-8.

Kim J, Ki SS, Lee SD, et al (2006). Elevated plasma osteopontin levels in patients with hepatocellular carcinoma. Am J Gastroenterol, 101, 2051-9.

Korita PV, Wakai T, Shirai Y, et al (2008). Overexpression of osteopontin independently correlates with vascular invasion and poor prognosis in patients with hepatocellular carcinoma. Hum Pathol, 39, 1777-83.

Lee HJ, Yeon JE, Suh SJ, et al (2014). Clinical utility of plasma glypican-3 and osteopontin as biomarkers of hepatocellular carcinoma. Gut and liver, 8, 177-85.

Llovet JM, Bruix J (2012). Hepatocellular carcinoma. Lancet, 379, 1245-55.

JM, Burroughs A, Bruix J (2003). Hepatocellular carcinoma. Lancet, 362, 1907-17.

Llovet JM, Di Bisceglie AM, Bruix J, et al (2008). Design and endpoints of clinical trials in hepatocellular carcinoma. $J$ Natl Cancer Inst, 100, 698-711.

Nagoshi S (2014). Osteopontin: Versatile modulator of liver diseases. Hepatol Res, 44, 22-30.

Rohde F, Rimkus C, Friederichs J, et al (2007). Expression of osteopontin, a target gene of de-regulated Wnt signaling, predicts survival in colon cancer. Int J Cancer, 121, 1717-23.

Sakaki M, Makino R, Hiroishi K, et al (2010). Cyclooxygenase-2 gene promoter polymorphisms affect susceptibility to hepatitis $\mathrm{C}$ virus infection and disease progression. Hepatol Res, 40, 1219-26.

Shang S, Plymoth A, Ge S, et al (2012). Identification of osteopontin as a novel marker for early hepatocellular carcinoma. Hepatology, 55, 483-90.

Sherman M (2011). Current status of alpha-fetoprotein testing. Gastroenterol Hepatol (N Y), 7, 113-4.

Sieghart W, Wang X, Schmid K, et al (2011). Osteopontin expression predicts overall survival after liver transplantation for hepatocellular carcinoma in patients beyond the Milan criteria. J Hepatol, 54, 89-97.

Simao A, Madaleno J, Silva N, et al (2015). Plasma osteopontin is a biomarker for the severity of alcoholic liver cirrhosis, not for hepatocellular carcinoma screening. BMC gastroenterology, 15,73 .
Singal A, Volk ML, Waljee A, et al (2009). Meta-analysis: surveillance with ultrasound for early-stage hepatocellular carcinoma in patients with cirrhosis. Aliment Pharmacol Ther, 30, 37-47.

Sopipong W, Tangkijvanich P, Payungporn S, et al (2013). The KIF1B (rs 17401966) single nucleotide polymorphism is not associated with the development of HBV-related hepatocellular carcinoma in Thai patients. Asian Pac J Cancer Prev, 14, 2865-9.

Spangenberg HC, Thimme R, Blum HE (2006). Serum markers of hepatocellular carcinoma. Semin Liver Dis, 26, 385-90.

Taketa K (1990). Alpha-fetoprotein: reevaluation in hepatology. Hepatology, 12, 1420-32.

Tangkijvanich P, Hirsch P, Theamboonlers A, et al (1999). Association of hepatitis viruses with hepatocellular carcinoma in Thailand. J Gastroenterol, 34, 227-33.

Wan HG, Xu H, Gu YM, et al (2014). Comparison osteopontin vs AFP for the diagnosis of HCC: a meta-analysis. Clin Res Hepatol Gastroenterol, 38, 706-14.

Wu CY, Wu MS, Chiang EP, et al (2007). Elevated plasma osteopontin associated with gastric cancer development, invasion and survival. Gut, 56, 782-9.

Yuen MF, Lai CL (2005). Serological markers of liver cancer. Best Pract Res Clin Gastroenterol, 19, 91-9.

Zhang CH, Xu GL, Jia WD, et al (2012). Prognostic significance of osteopontin in hepatocellular carcinoma: a meta-analysis. Int J Cancer, 130, 2685-92.

Zhou C, Zhou HJ, Zhang XF, et al (2013). Postoperative serum osteopontin level is a novel monitor for treatment response and tumor recurrence after resection of hepatitis B-related hepatocellular carcinoma. Ann Surg Oncol, 20, 929-37. 